\title{
GROUND-PENETRATING RADAR IMAGING TECHNIQUES APPLIED IN 3D ENVIRONMENT: EXAMPLE IN INACTIVE DUNES
}

\author{
David Lopes de Castro ${ }^{1}$, João Andrade dos Reis Júnior², Washington Luiz Evangelista Teixeira ${ }^{3}$, \\ Victor de Albuquerque Silva ${ }^{4}$ and Francisco Pinheiro Lima Filho ${ }^{1}$
}

\begin{abstract}
The increased use of Ground-Penetrating Radar (GPR) in several areas of knowledge has introduced an impressive number of new methodological procedures, adapted from other areas, such as seismic reflection, or developed specifically for the GPR. A summary of the advances in acquisition, processing and interpretation of GPR data is presented in this paper. Some of the techniques were applied to a 3D GPR survey in a study area, whose substrate is composed by sedimentary sequences of paleodunes or inactive dunes, located in the outer courtyard of the Department of Geology (DEGEO) of the Universidade Federal do Rio Grande do Norte (UFRN), Brazil. A GPR cube was generated from a regular grid of GPR in-lines and cross-lines, spaced $0.5 \mathrm{~m}$. A filtering routine was applied. For each processing step, the changes in the signal content in the time and frequency domains were analyzed. Common midpoint (CMP) sections and hyperbolas of buried pipes constrained the construction of a subsurface velocity model, allowing the migration and time/depth conversion of the radargrams. Analysis of instantaneous, amplitude, and geometrical attributes and concepts of seismic stratigraphy were applied in the migrated GPR cube to define five stratigraphic sequences and their paleo-reliefs. Based on the radar facies internal geometry, some considerations were established about the depositional environment of the surveyed area.
\end{abstract}

Keywords: GPR, 3D imaging, processing, attribute analysis.

RESUMO. A expansão do uso do GPR nas mais diversas áreas do conhecimento tem contribuído para o desenvolvimento de novos procedimentos metodológicos, decorrentes da adaptação de outros métodos geofísicos, principalmente a sísmica de reflexão, ou desenvolvidos especialmente para o GPR. Uma síntese dos avanços nas etapas de aquisição, processamento e interpretação é descrita no presente artigo. Algumas das técnicas analisadas foram aplicadas em dados GPR obtidos em um levantamento realizado segundo uma malha retangular, em uma área de estudo situada no interior do campus da Universidade Federal do Rio Grande do Norte (UFRN). 0 substrato imageado é constituído por camadas de sedimentos arenosos siliciclásticos, de origem eólica costeira, depositados sobre rochas do Grupo Barreiras. Um volume GPR foi gerado a partir de uma malha regular de linhas longitudinais e transversais, espaçadas de 0,5 m. Uma rotina de filtragem dos dados GPR é proposta, sendo as alterações no conteúdo do sinal eletromagnético (EM) analisadas nos domínios do tempo e frequência para cada etapa do processamento. Seções de ponto médio comum (CMP) e hipérboles de tubulações soterradas permitiram a confecção de um modelo de velocidades da subsuperfície e a migração e conversão tempo/profundidade dos radargramas. Análise de atributos instantâneos, de amplitude e geométricos, além de técnicas de interpretação sismoestratigráficas foram aplicadas no volume GPR migrado para definir cinco sequências estratigráficas e seus paleorelevos. Com base nas geometrias internas das radarfácies, foram tecidas algumas considerações sobre a geometria e arquitetura dos depósitos investigados.

Palavras-chave: GPR, imageamento 3D, processamento, análise de atributos.

\footnotetext{
${ }^{1}$ Universidade Federal do Rio Grande do Norte, Programa de Pós-graduação em Geodinâmica e Geofísica, Departamento de Geologia, Campus Universitário s/n, Lagoa Nova, 59078-970 Natal, RN, Brazil. Phone: +55(84) 3342-2277 (R. 220) - E-mails: david@geologia.ufrn.br; pinheiro@geologia.ufrn.br

2Universidade Federal Rural da Amazônia - Campus Parauapebas (PA) - E-mail: junioreis03@yahoo.com.br

$3^{3}$ Departamento Nacional de Obras Contra as Secas, CEST/RN, Campus Universitário s/n, Lagoa Nova, 59078-970 Natal, RN, Brazil. Phone: +55(84) 3342-2277 (R. 220)

- E-mail: wasluiz@gmail.com

4Petrobras, Unidade de Operações do Rio Grande do Norte e Ceará (UO-RNCE), Natal, RN, Brazil - E-mail: victor.albuquerque@petrobras.com.br
} 


\section{INTRODUCTION}

In recent decades, the Ground-Penetrating Radar (GPR) has been acclaimed as one of the most important geophysical imaging techniques of the shallow subsurface, to a few tens of meters, in the areas of Geosciences, Engineering, Archaeology and Forensic Sciences (Jol, 2009). The popularization of this geophysical method through theoretical (Davis \& Annan, 1989; Annan, 1996; Roberts \& Daniels, 1996), experimental (Redman et al., 1994; Lai et al., 2006) and case studies (Rossetti et al., 2001; De Castro \& Castelo Branco, 2003; Forte et al., 2012) has caused a rapid and concomitant progress in the areas of acquisition, processing and interpretation of GPR data. Acquisition techniques has advanced greatly with more efficient generation of the transmitted electromagnetic signal and its digital sampling, improved shielding of the antennas against ambient noise and increased number of available antennas operating on different EM pulses frequencies. More portable systems, coupled with odometers, GPS and total stations (Böniger \& Tronicke, 2010), allow more accurate spatial positioning of each GPR trace, which provides both high precision three-dimensional surveys and surveys covering larger areas, with GPR being installed in vehicles and vessels (Souza et al., 2002; Lahouar \& Al-Qadi, 2008).

The GPR data digital processing techniques have developed greatly in the last 15-20 years (Jol, 2009). In fact, one can easily see that a large proportion of papers published until the mid2000s (e.g., Davis \& Annan, 1989; Pereira et al., 2003) presents GPR data with little or no processing beyond the traditional dewow filter for attenuation of low-frequency noise associated with electromagnetic induction (Annan, 1996), band-pass filters to eliminate noise outside the GPR signal frequency bandwidth, and some gain functions like Automatic Gain Control (AGC) and Time Varying Gain (TVG) to equalize the amplitudes of the deeper reflections. Studies by Hollender \& Tillard (1998) and Xavier Neto \& Medeiros (2006) analyzed in detail the contents of the GPR signal and proposed more sophisticated procedures to improve the signal/noise ratio, especially in situations unfavorable for GPR use regarding subsurface material composition and its structural complexity. Concepts such as "good quality GPR data are the ones that require no processing" were replaced by the concept that information from buried targets can still be extracted from noisy GPR data using advanced processing approaches, thereby extending the GPR operating limits.

In terms of visualization and interpretation of GPR sections, commercial or public domain softwares currently offer high-resolution radargrams, with numerous choices of color palettes and visualization features in 3D environment. Incorporation of GPR signal attributes analysis (Böniger \& Tronicke, 2010; Forte et al., 2012), techniques to trace reflectors in a semi-automatic or automatic way and obtain three-dimensional horizons, and generation of synthetic radargrams (Carcione et al., 2000; Cassidy, 2007) have made the geometric interpretation of deposits and strata with time line features less dependent on subjective decisions on the part of the data interpreter, based on a mental database of past examples (Chopra \& Marfurt, 2005). Additionally, the development of new computational algorithms has enabled the correlation of specific GPR signal characteristics with petrophysical properties of the investigated materials. For example, techniques such as Amplitude vs. Offset (AVO) can aid the imaging of porosity and saturation in interstitial fluids in subsurface (Deeds \& Bradford, 2002).

This study discusses the advantages and limitations of the application of GPR data acquisition, processing and interpretation techniques, developed in recent years. Such procedures are applied in a test area, whose GPR signature of sedimentary strata allows assessments of their contributions to subsurface imaging.

Regarding the geophysical acquisition methodological procedures, a proposal for a GPR survey over a regular grid of parallel lines oriented in two orthogonal directions is presented. Thus, the strong tendency of the reflectors to stretch in the direction orthogonal to the survey lines raised in a single direction is greatly attenuated, generating more realistic 3D GPR volumes. For the data processing step, some already established routines are tested by analyzing the changes in the content of the geophysical signal in the time and frequency domains and their results in the final GPR sections. In the radargrams interpretation phase, statistical and mathematical attributes are applied in order to highlight specific features of the imaged strata, making the interpretation process less subjective. Finally, the use of seismic sections interpretation techniques applied in a 3D virtual environment allows mapping the depositional architecture and its bounding surfaces, in order to parameterize the current sedimentary deposits or in outcrops considered analogous to aquifers and/or petroleum reservoirs.

\section{D GPR ACQUISITION}

Proper imaging of the subsurface depends mainly on the quality of the GPR system, the right choice of antennas (frequency of the transmitted signal), the data acquisition parameter configuration, the electrical properties of the medium, external interference (electrical wires, fences, metal pipes, etc.), the study area accessibility conditions and the spatial distribution of GPR data over the target(s). After all operational aspects of the acquisition of GPR profiles are optimized, one must consider that 3D surveys provide 
not only better conditions to identify the investigated targets, but also allow mapping their internal three-dimensional geometries.

Daniels et al. (1997) generically described a 3D GPR survey as an acquisition of parallel GPR lines separated by distances not much greater than half the wavelength of the transmitted EM signal. Even today, in most surveys considered as 3D, the GPR profiles are acquired along parallel lines in a single direction (e.g., Negri et al., 2008; Kadioglu, 2008; Hermozilha et al., 2010). However, a problem related to this type of survey, also called pseudo3D survey (Novo et al., 2008), is the presence of reflectors excessively stretched orthogonally to the GPR lines due to subsampling in this direction (aliasing). According to Nyquist criteria (1928), an appropriate sampling should be greater than a quarter of the signal wavelength. In the current GPR surveys with $400 \mathrm{MHz}$ antennas, GPR traces are usually sampled from 0.02 to $0.05 \mathrm{~m}$ along the direction of the GPR sections, while in the perpendicular direction, the data are generally spaced from 0.5 to $1.0 \mathrm{~m}$. This difference in sampling of more than an order of magnitude is not properly corrected in generating GPR volumes, even employing the most sophisticated interpolation techniques available in the current software programs. A simple alternative to overcome this problem is the acquisition of GPR data in both orthogonal directions. This procedure is ordinarily adopted in seismic reflection surveys, although in the case of GPR, volumes as accurate as $3 \mathrm{D}$ seismic cubes are not expected. This is due to the fact that EM waves propagate with directional components (Annan et al., 1975), unlike the spherical seismic waves. In theory, this problem can be circumvented by maintaining the same orientation of the antennas when surveying both longitudinal and transverse lines, usually in the direction perpendicular to the Ey polarization component of the electric field (Versteeg, 1996).

Grasmueck et al. (2005) proposed a higher line density to generate high-resolution 3D GPR imaging. Based on theoretical and practical analysis of the GPR signal, these authors believe that a spatial sampling of up to $25 \%$ of the wavelength in all directions is required for generating $3 \mathrm{D}$ volumes without distortion due to subsampling between GPR lines (aliasing). For $400 \mathrm{MHz}$ antennas, the recommended spacing of the GPR grid is in the 0.025 to $0.06 \mathrm{~m}$ range. Such dense data distribution requires additional operational efforts related to acquisition time, clearing and leveling of surveyed surface and an accurate planialtimetric positioning system for each GPR line acquired. However, less dense 3D GPR surveys are preferable for areas with difficult access and/or less complex geological context, and when the study does not require decimeter accuracy survey, such as this research.

Another important advantage of GPR surveys along longitudinal and transverse lines is the ability to image more precisely elongated targets along a preferential direction (faults, tubes, etc.). Because the preferred directions of buried targets are not always known in advance, choosing one sole direction for GPR sections may prove unsuitable. In Figure 1, a buried pipeline with direction approximately parallel to the $X$ axis of the survey grid presents a GPR signature in the form of a hyperbola on line 20 (cross-line), while in-line 15 (in-line) a subparallel reflector is observed. The detection of this pipeline would be unlikely in a pseudo-3D survey with lines only along the $X$ axis and spaced $0.5 \mathrm{~m}$. In this example, the pipeline could even be misinterpreted as a sedimentary stratum.

In order to evaluate the increase in the resolution of GPR volumes, a survey with longitudinal and transverse lines was performed in a study area located in the outer courtyard of the Department of Geology (DEGEO) of the Universidade Federal do Rio Grande do Norte (UFRN) in Natal (Fig. 2). A total of 42 GPR profiles were acquired along the N-S and E-W directions with spacing of $0.5 \mathrm{~m}$, forming a square with a side of $10 \mathrm{~m}$. A SIR3000 system with $400 \mathrm{MHz}$ antennas, manufactured by Geophysical Survey Systems Inc. (GSSI) was used to acquire the GPR traces, spaced every $0.02 \mathrm{~m}$. Each GPR trace contains 512 samples, distributed in a time window of $100 \mathrm{~ns}$. The distances between the lines were obtained with an odometer and GPR lines were marked on the ground with stakes. Topographical variations were not measured since the terrain is mostly flat. Additionally, two common midpoint (CMP) sections were performed with $80 \mathrm{MHz}$ bistatic antennas for velocity analysis of EM waves in the directions of the GPR lines (Fig. 2). The initial spacing of the antennas was $1.0 \mathrm{~m}$, moving $0.2 \mathrm{~m}$ further apart for each new reading reaching maximum spacing of the order of $35 \mathrm{~m}$.

From the geological point of view, this area is located on the Rio Grande do Norte coastal region and the imaged deposits correspond to aeolian paleodunes, set by the vegetation and situated within the SW edge of Parque das Dunas in Natal. According to Angelim (2006), in Rio Grande do Norte State, the coastal aeolian deposits of paleodunes consist of fine to medium, well selected, mature, whitish sands, with grain fall structures and low-angle cross-stratification. They form barchan, parabolic and barchanoid dunes, which represent the dunes and interdunes facies of the coastal plain. According to morphological criteria, Barreto et al. (2004) distinguish the inactive dunes in simple and compound parabolic, with sharp or tenuous forms, typically with vegetation. The study site lies on the boundary between these two types, with flat relief and thin vegetation cover. The contribution of Barreiras Formation as source rock for the dunes in the region must have varied in direct relation to its degree of exposure and dissection (Barreto et al., 2004). 


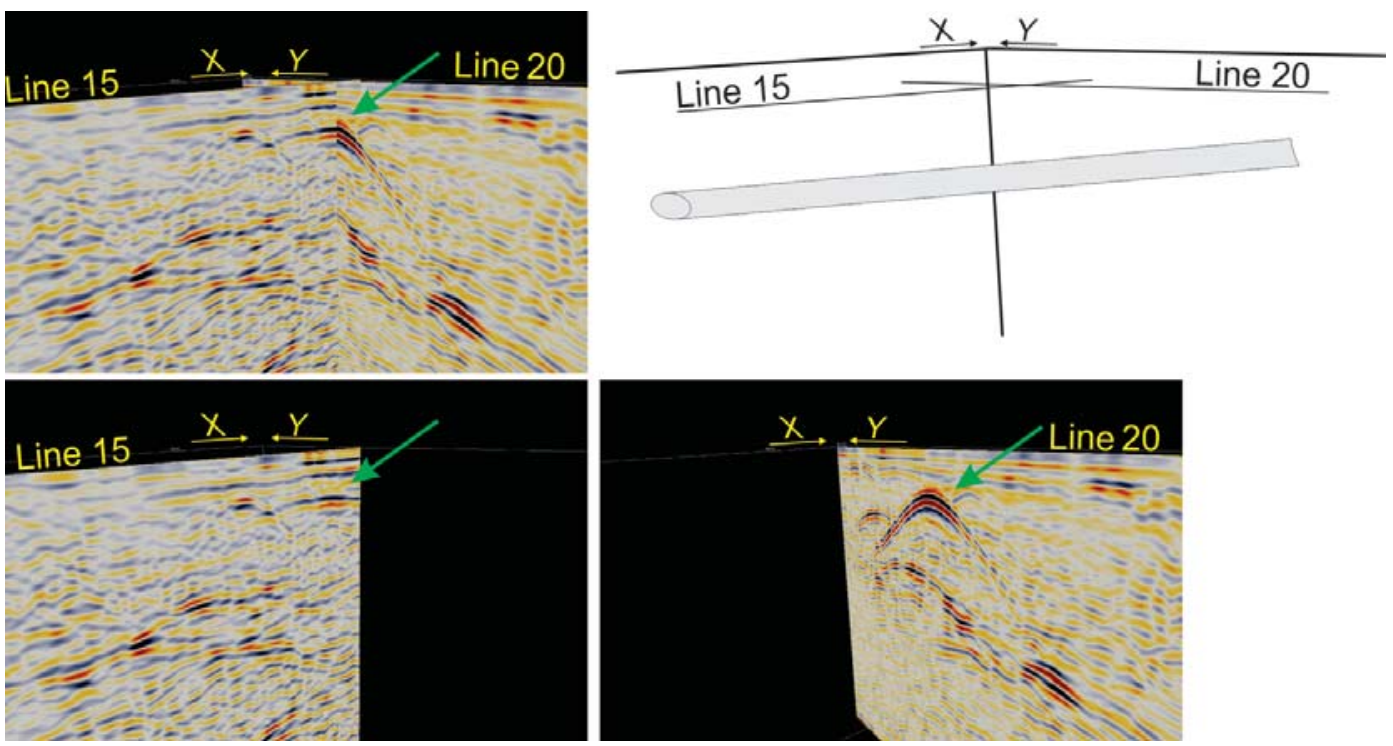

Figure 1 - GPR signal of a buried pipeline (green arrows), observed along the In-line $20(S \rightarrow N)$ and Cross-line $15(W \rightarrow E)$.

\section{PROCESSING AND VELOCITY ANALYSIS}

The GPR signal acquired by the receiving antenna can be described by a convolution of a series of time functions, each representing the response of the physical medium to each of the GPR system components, resulting in the reflections observed in the radargrams (Daniels, 2008). Various noise sources are added to this signal, which still undergoes attenuation as a result of absorption, scattering and spherical divergence in the subsurface (Xavier Neto \& Medeiros, 2006). Thus, the processing step should promote the attenuation of the GPR signal contents that are not directly related to variations in electromagnetic impedance of the subsurface and correct the effects of signal attenuation with depth.

Despite the consensus on the need to apply a basic processing series, the use of more advanced techniques is quite controversial and guided by subjective aspects such as the personal opinion of the interpreter, his experience and training, as well as the nature of the data and target characteristics. According to Daniels (2008), the main objective of the GPR signal processing is to produce an image that can actually be interpreted by the professional in charge or identify a response of a target with respect to a known test procedure or a synthetic model. Thus, the GPR processing can be considered as a sequential application of mathematical operators, subjectively directed by the interpreter to produce a GPR section as close as possible to the EM signal one expects to find in the subsurface (Cassidy, 2009). However, several authors (e.g., Hollender \& Tillard, 1998; Young \& Sun, 1999; Xavier Neto \& Medeiros, 2006; Daniels, 2007) analyzed the contents of the GPR signal in the time and frequency domains to pro- pose processing sequences based on the characteristics, properties and physical phenomena of the EM pulses and the dielectric medium through which they propagate. The theoretical understanding of the effect of each filter on the GPR data contributes to diminish the purely subjective choice of processing techniques.

The basic steps proposed by these and other authors were applied to GPR data collected in the study area. The results are presented and discussed in the light of the changes in the content of the filtered signal (Fig. 3). In addition, a Kirchoff type migration was applied to the GPR sections to collapse the diffractions generated by underground pipelines and correct positioning of reflectors, especially those tilted. Processing normally begins with zero time correction of the GPR lines to adjust the first reflection at the ground surface. Variations in arrival time of direct waves due to thermal drift, electronic instability, differences in cable length, among other disturbances generated in antennas, can also be eliminated at this stage (Cassidy, 2009). A constant value of 9.2 ns was subtracted from all GPR survey lines without changing the signal amplitude spectrum (Figs. 3A and 3B).

In GPR surveys using GSSI instruments, an extra processing step is required to remove the gain occurred during the acquisition of the GPR data. In this case, a filter is used on each line independently, which applies an inverse gain function to the values stored in the raw data file header. As a result, one obtains the original amplitudes of the reflections without the amplification of the time variant introduced during the survey. This step is important to standardize the data of different GPR sections, especially if these were acquired with different gain functions, as well as to 


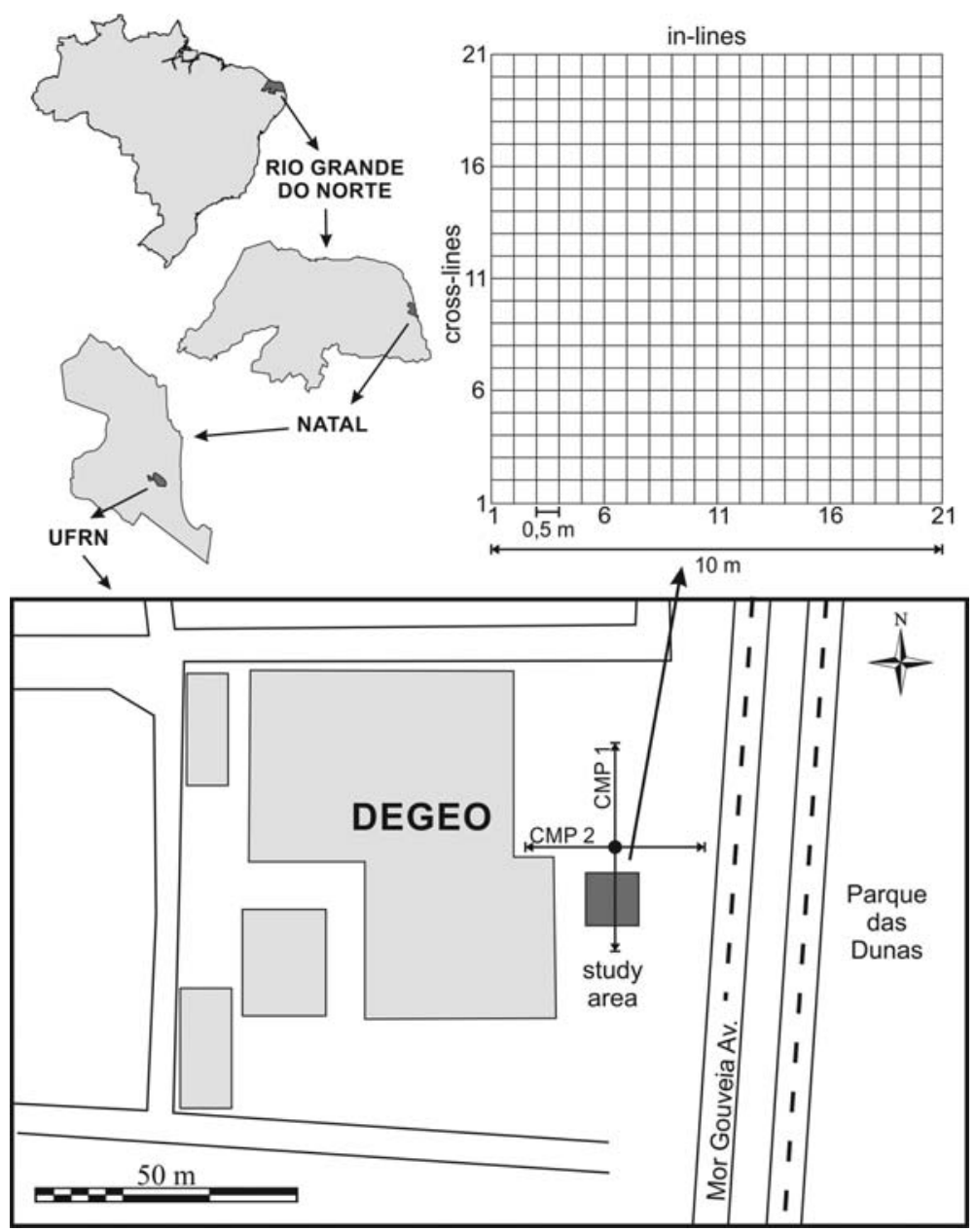

Figure 2 - Location of the study area on the outdoor patio of the Departamento de Geologia (DEGEO) of the Universidade Federal do Rio Grande do Norte (UFRN) and spatial distribution of the GPR lines. The GPR sections were acquired in zigzag mode.

utilize the real amplitudes of the reflections. After applying this filter (Line 2 - Figs. 3A and 3D), the amplitudes of the first reflectors become much larger than those of the deeper reflectors, highlighting the strong signal attenuation with depth. The signal spectrum amplitude becomes quite smooth after the removal of the gain function, with an approximately Gaussian distribution centered around $250 \mathrm{MHz}$ (Fig. 3D). This frequency lies offset from the main frequency of $400 \mathrm{MHz}$ of the antennas employed in the survey.

This GPR signal displacement in the frequency domain results from a severe temporal stretch of the propagated pulse due to its dispersion in the dielectric medium, as explained by Bano (1996). Xavier Neto \& Medeiros (2006) present a methodological procedure to correct this attenuation effect based on gain functions and spectral balancing, as will be discussed later.
The GPR trace shows a low-frequency content (wow) caused by EM saturation of the received signal due to the arrivals of direct waves, and the effects of the antenna's inductive coupling (Annan, 1996). For proper correction of this inherent and non-linear EM interference a high-pass or optimized median filter, called dewow, is employed. An average value is calculated for each record of each trace, adopting a temporal window of about a main period of the EM wave. This mean value is then subtracted from the center value. In the study area, this low-frequency noise is concentrated up to $40 \mathrm{MHz}$ (Fig. 3D). For its removal, a dewow filter with a $4 \mathrm{~ns}$ time window was applied, with very satisfactory results from the spectral point of view (Fig. 3E). Analyzing Figure 4, which shows a comparison between the raw and filtered traces in the time domain, we find only a slightly more pronounced difference between the initial and final times of the GPR signal. Although subtle in the 

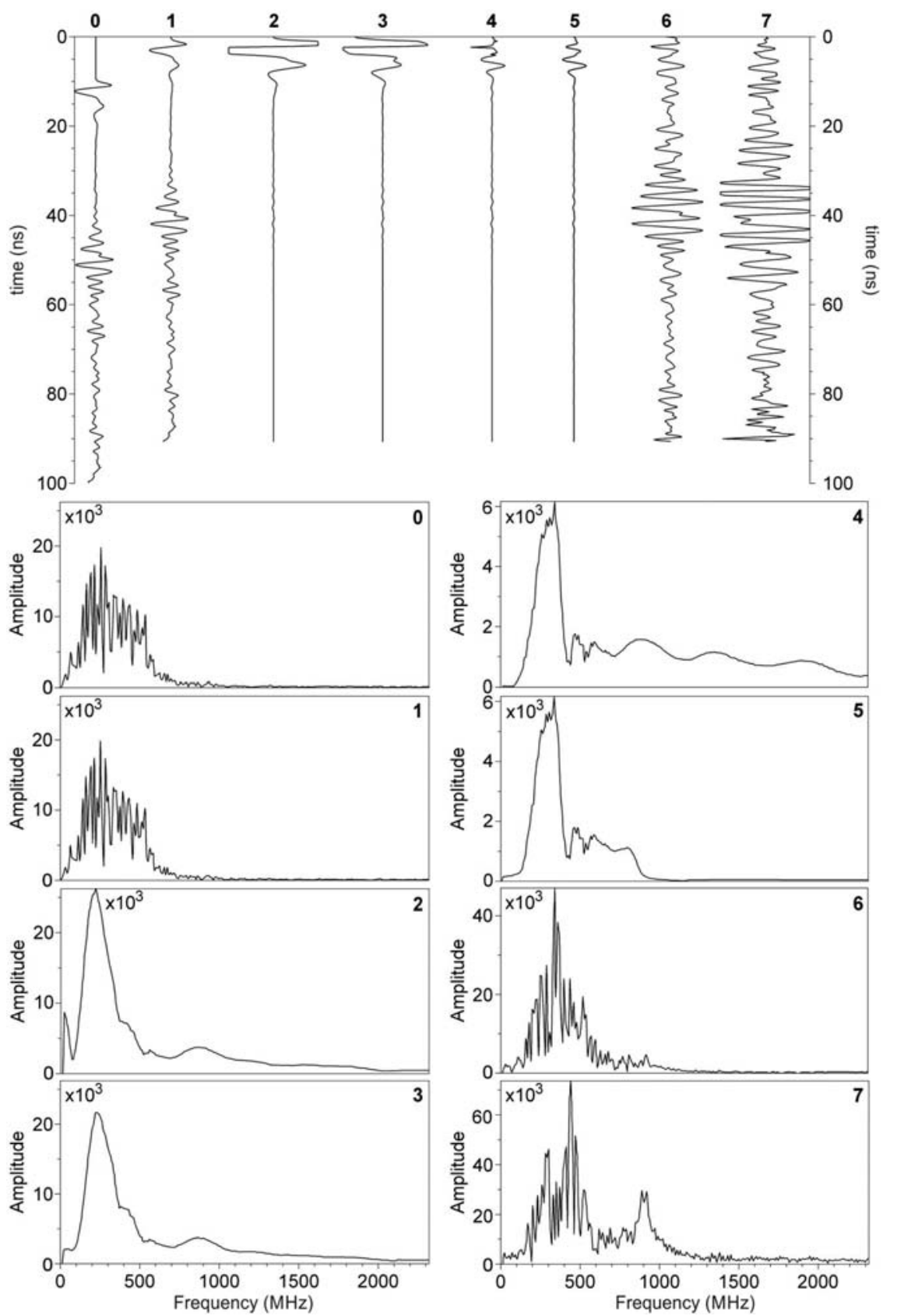

Figure 3 - Variations in the GPR signal in the time (A) and frequency (B to I) domains for each stage of data processing. Trace 0 represents the raw data and the other traces the seven processing steps described in the text. Note that the scales of the vertical axis (amplitudes) were not fully normalized to highlight the variations of the signal amplitude spectrum at different processing stages.

study area radargrams, the wow effect can be critical in situations with low signal/noise ratio.

The electromagnetic induction between the antennas corresponds to a direct electromagnetic wave propagated through the air with little attenuation, generating amplitudes well above the reflections in the subsurface (traces 2 and 3 - Figs. 3A, 3D and $3 \mathrm{E})$. This phenomenon occurs at the same time when the bedrock reflections arrive at the receiving antenna. The result of this superposition of signals is a high amplitude saturation that conceals mostly the shallower reflectors (Xavier Neto, 2006). The correction of the EM induction effect, suppressing the direct waves and removing background noise, is performed by subtracting from each trace the average of all traces of the GPR section (Cassidy, 2009). This process, known as background removal or 


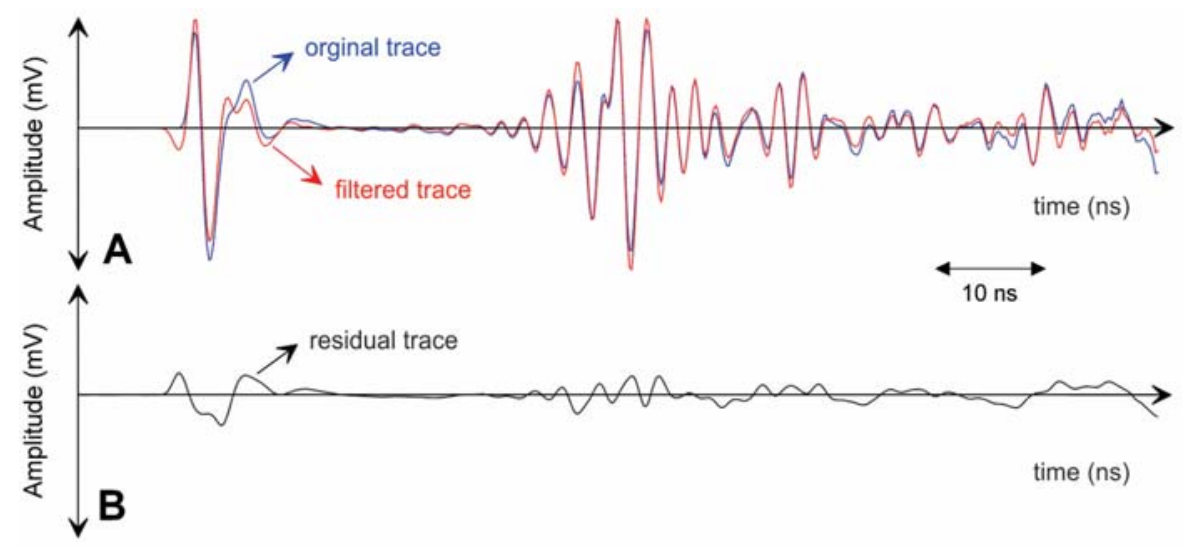

Figure 4 - Comparison between an original and corrected GPR trace with dewow filter (A) and the difference between them (B).

subtracting average, also attenuates horizontal and periodical reflections (ringing) due to the strong coupling between the antennas and the ground and horizontal reverberations of the more superficial layers. This coherent noise occurs most intensely in conductive and dispersive media and can conceal the deeper reflectors, imposing plane-parallel reflections with strong amplitudes on the GPR signal. After applying this filter, the reflections of the direct waves are being suppressed (compare traces 3 and $4-$ Figs. 3E and 3F) and the amplitudes in the frequency domain are reduced by a factor of about 4 (Fig. 3F). The GPR signal was more centered at about the $300 \mathrm{MHz}$ frequency, with the content below $100 \mathrm{MHz}$ considerably attenuated.

The next step consists of filtering the GPR data to attenuate system or cultural noise, highlight particular aspects of the data, such as plane-parallel reflectors or diffractions, and improve the visual quality and interpretation of the radargrams (Cassidy, 2009). The simple bandpass filters are very efficient for removing noise from low and high frequencies, while more sophisticated filters, such as 2D filters, which operate simultaneously in time and space, are applied specifically to problems such as excessive ringing or impulsive noise, among others (Annan, 1999). Because the data acquired in the study area had little noise, we chose to apply a trapezoidal bandpass filter to eliminate the signal content outside the region extending symmetrically from the center frequency of the antennas, and having a bandwidth equal to at least 1.5 times this value, as suggested by Cassidy (2009). The bandpass filter, which generated even less noisy GPR sections, had the cutoff bands set at 100-200 MHz and 800-900 MHz for the low and high frequencies, respectively (Fig. 3G).

Using the gain function is essential to reconstruct the amplitudes of the deeper reflectors strongly attenuated by absorption, dispersion, and spherical divergence of the EM pulse during propagation in a dielectric medium (Annan, 1996). These functions use a multiplier factor for successive regions, or time windows, of the trace. The most common are spherical and exponential corrections (geometrical spreading correction - SEC or energy decay; Yilmaz, 2008), automatic gain control (AGC) and constant, linear or exponential mathematical operators. However, implementation of these functions not only changes the relative amplitudes of the reflections, but also the spectral content of the data (Figs. 3C and 3D). Therefore, Cassidy (2009) recommends using gain functions only after data filtering, and before, only when the effects of the gain on the spectral content of the signal are fully understood since this is a non-linear process (Annan, 1999).

The gain function chosen was the SEC. According to Xavier Neto (2006), this filter operates on GPR data by applying a linear gain function to correct the effect of decreasing energy with distance from the source (geometrical spreading), and an exponential gain function, which offsets the effect of amplitude loss by absorption. SEC retains information on the relative amplitudes both in time and space, which is important for detailed interpretation of the radargrams. Trace 6 of Figures $3 \mathrm{~A}$ and $3 \mathrm{H}$ represents the filtered data after applying the gain function. The amplitudes were quite amplified by keeping some consistency with the original amplitude (Traces 0 and 1). The amplitude spectrum of the GPR signal after the gain ranges from 150 to $600 \mathrm{MHz}$, peaking at $325 \mathrm{MHz}$ (Fig. 3H).

Since the next processing step, migration of GPR sections, requires knowledge of the EM waves propagation velocities, an analysis was performed on sections of common offset, based on the adjustment of hyperbolas generated by diffraction on a pipeline in the study area (Fig. 1), and two common midpoint (CMP) sections through the velocities spectrum (semblance). In the case of diffraction hyperbolas, a theoretical hyperbola is fitted 
to each diffraction in the radargram. As the shape of the hyperbola depends on the propagation velocity of EM waves in the medium, it is possible to obtain such velocities interactively directly from the radargram. The length and the radius of the theoretical hyperbola are modified graphically in the radargrams for better overlap with the diffraction hyperbolas. The 21 longitudinal GPR survey lines intersect perpendicularly the aforementioned pipeline, which allowed observing velocity variations from 0.13 to $0.14 \mathrm{~m} / \mathrm{s}$ along the area for a travel time of about $9.5 \mathrm{~ns}$.

In the CMP sections, the velocity spectrum relative to the EM pulse travel time describes the variations of the coherence factor at each point of the time/velocity matrix, which is calculated by the sum of the cross-correlation of the normalized reflections energies (Yilmaz, 2008). The peaks in the contoured coherence factor values correspond to velocities that match a particular time in which a reflection phase of the CMP section occurs (Keary et al., 2009). The final result is a $1 \mathrm{D}$ velocity model for one CMP, or $2 \mathrm{D}$ for a set of CMPs, of the layers in subsurface used for the time/depth conversion and GPR sections migration.

The two CMP sections were perpendicular to each other and parallel to the longitudinal and transverse lines of the 3D survey (Fig. 2). Bi-static, $80 \mathrm{MHz}$ antennas were used to acquire the GPR traces, spaced $20 \mathrm{~cm}$ apart in a time window of $250 \mathrm{~ns}$ (Fig. 5A). The distance between the antennas (offset) ranged from 1.0 to $38.2 \mathrm{~m}$ (CMP 1) and $32.6 \mathrm{~m}$ (CMP 2). The dewow filter and the spherical and exponential correction (SEC) were applied to the data to eliminate the effect of EM induction of the antennas and the GPR signal attenuation with depth, respectively.

The CMP velocity spectra show coherence factor peaks ranging from 0.12 to $0.17 \mathrm{~m} / \mathrm{ns}$ (Fig. 5B). Between the times of 80 and $110 \mathrm{~ns}$ and 145 and $170 \mathrm{~ns}$, the CMP 1 shows two bands with a velocity exceeding $0.17 \mathrm{~m} / \mathrm{ns}$, missing in the CMP 2. Although these differences are incipient, interval velocity curves appear, in principle, conflicting in the deeper portions (Fig. 5C). In the first $2.7 \mathrm{~m}$ deep, lies the most superficial layer with a velocity of about $0.155 \mathrm{~m} / \mathrm{ns}$ at both CMP sections. Although this value is slightly higher than those obtained by analysis of hyperbolas ( 0.13 to $0.14 \mathrm{~m} / \mathrm{ns}$ ), results are considered consistent. According to Cassidy (2009), CMP and hyperbolas analysis techniques tend to produce approximate velocity values with errors and variance above $10 \%$, which is compatible with the maximum difference of $0.025 \mathrm{~m} / \mathrm{ns}$ between the two velocity analysis techniques obtained in the study area.

Below the depth of $2.7 \mathrm{~m}$, in CMP 1 the interval velocity increases to $0.17 \mathrm{~m} / \mathrm{ns}$ until a depth of $8.2 \mathrm{~m}$, and to $0.175 \mathrm{~m} / \mathrm{ns}$ after that, while in CMP 2 velocity drops to $0.12 \mathrm{~m} / \mathrm{ns}$, returning to $0.173 \mathrm{~m} / \mathrm{ns}$ below $9.1 \mathrm{~m}$. Such differences may be attributed to a combination of the following factors: a) asymmetry in the propagation of EM waves in dielectric medium since the CMP sections were surveyed with antennas positioned in orthogonal directions; b) lateral heterogeneities of the bedrock, both in composition and sheet dipping; and c) centimeter variations of topography, not corrected in this survey.

The interval velocity curves (Fig. $5 \mathrm{C}$ ) served as a basis to generate a $1 \mathrm{D}$ velocity model of the subsurface and to promote the migration of GPR sections and the time/depth conversion. This processing step eliminates diffractions and corrects the position in depth of the reflectors, especially the more inclined (Yilmaz, 2008). The Kirchhoff migration method was chosen because it offered the best collapse of diffractions in migrated radargrams with respect to other migration techniques tested (diffraction stack, $\mathrm{f}-\mathrm{k}$ and finite difference). The Kirchhoff migration is based on the integral solution of the wave equation. A weighted sum for each point of the profile is carried out on a theoretically calculated hyperbola for a preset bandwidth. This spatial window represents the number of traces to be summed (Yilmaz, 2008). A spatial window of 50 traces was the best fit to the observed diffractions in the study area (Fig. 1), considering both sides of hyperbola.

Trace 7 of Figures $3 \mathrm{~A}$ and $3 \mathrm{I}$ represents the filtered data after application of Kirchhoff migration. The amplitudes were quite amplified, while still maintaining some consistency with the original ones (compare traces 1 and 6 ). Like for the non-migrated data, the amplitude spectrum of the migrated GPR signal also concentrates in the 150 to $600 \mathrm{MHz}$ range (Fig. 3H). However, the peak is shifted from 325 to $440 \mathrm{MHz}$. This frequency is closer to the center frequency of the antennas ( $400 \mathrm{MHz}$ ). In addition, another peak appears at $900 \mathrm{MHz}$ as an undesirable byproduct of migration. This peak could be easily removed by applying a low-pass filter. However, as the migrated radargrams already have a good resolution; application of another processing step was considered unnecessary.

A comparison of the GPR data before and after the application of filters is shown in Figure 6. The GPR section was corrected to zero time; EM induction and signal attenuation were corrected with depth. Direct waves and background effects were removed, as well as low and high frequency noise. The gain function optimized the amplitude equalization in the radargram, especially for the uppermost reflectors of the GPR sections (up to $4 \mathrm{~m}$ deep). Finally, migration allowed collapsing of diffractions, repositioning of reflectors, especially the most tilted, and executing time depth conversion. 

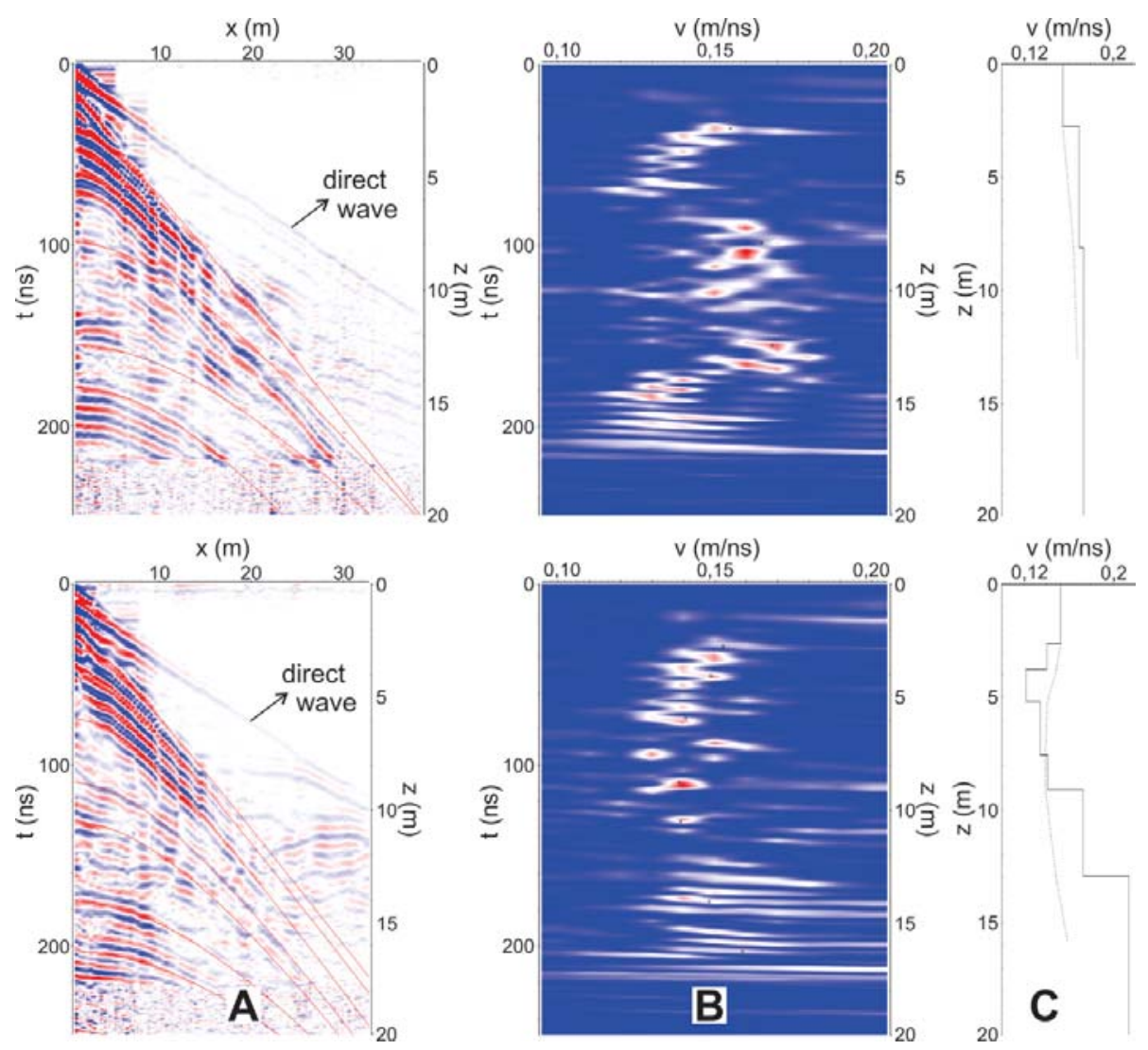

Figure 5 - Velocity analysis of the two CMP sections in the study area (Fig. 2). (A) CMP 1 (top) and CMP 2 (bottom); (B) Spectra of velocity vs. time (semblance); and (C) Velocity models of the investigated subsurface.
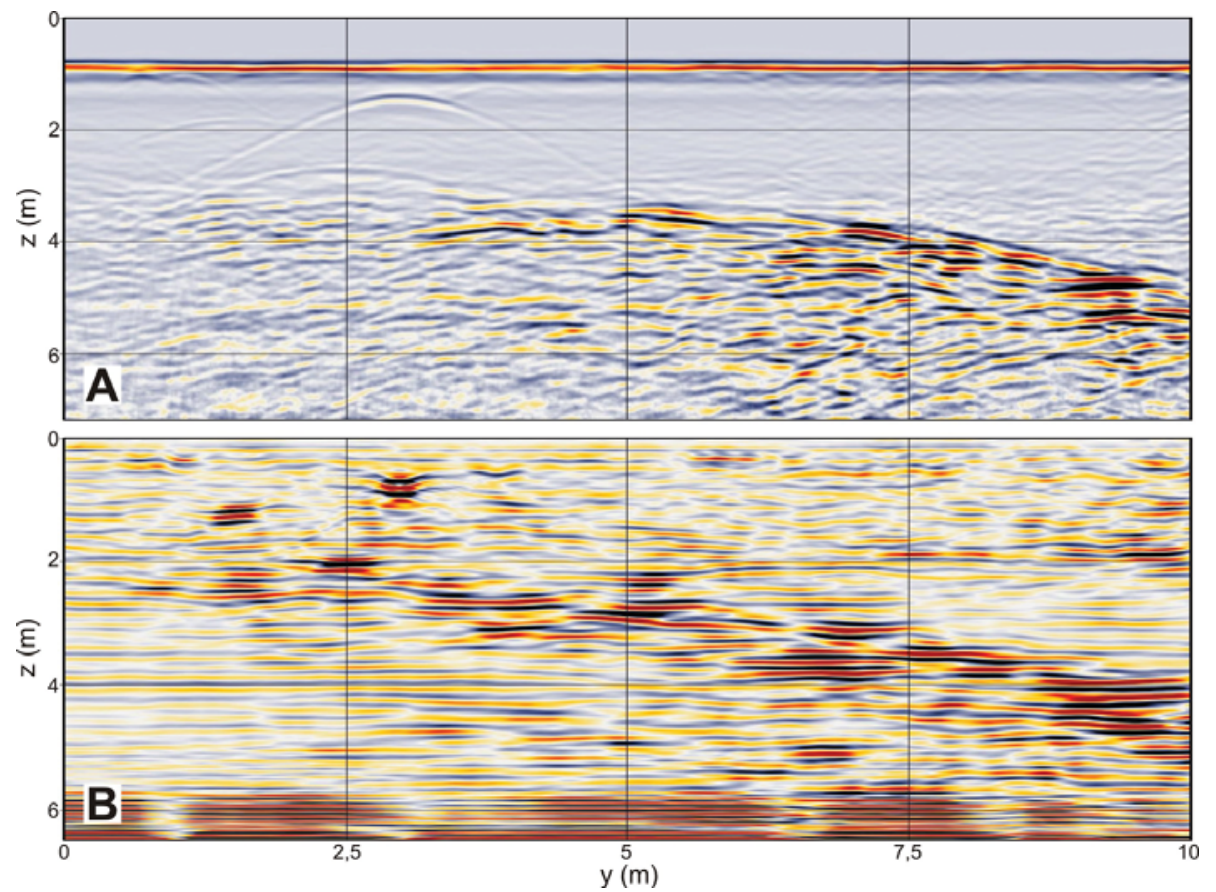

Figure 6 - Original (A) and processed (B) GPR section of the In-line 20. 


\section{ATTRIBUTES ANALYSIS}

According to Chopra \& Marfurt (2005), a seismic or, as in our case, a GPR attribute, is a quantitative measure of a geophysical characteristic of interest. Attributes analysis has been integrated into seismic interpretation since the 1930s and more recently into GPR interpretation (Cassidy, 2009). Currently, there are over 50 types of seismic attributes used for the interpretation of geological structures, stratigraphy and petrophysical properties of rocks, and interstitial fluids (Chopra \& Marfurt, 2005). Many of these attributes have been applied to GPR data directly (Senechal et al., 2000; Corbeanu et al., 2002, among others), or adapted to the specific characteristics of the EM waves propagation (Böniger \& Tronicke, 2010; Forte et al., 2012).

The analysis of attributes becomes even more important considering that the dynamic range of the data produced on a monitor screen is approximately 10 to $20 \mathrm{~dB}$, whereas the dynamic range of a GPR system is at least $60 \mathrm{~dB}$ (Cassidy, 2009). In other words, only 20 to $30 \%$ of the information contained in the radargrams can be displayed on the monitor. Additional information about specific features of the studied substrate, which is contained in the GPR data, can be extracted by calculating attributes of the signal. However, the simultaneous use of multiple attributes can lead to interpretations unfounded by the reality of the investigated environment. Chopra \& Marfurt (2005) and Barnes (2007) warn of the preferential use of those attributes that are associated with investigated physical properties and features of the study area.

One of the most basic attribute sets is obtained by the complex trace analysis. The seismic trace or, as in our case, the GPR signal can be treated as a complex function, and provide through Hilbert transform instantaneousaneous attributes such as amplitude, phase, frequency, among others (Taner et al., 1979).

Instantaneous Amplitude is sensitive to changes in acoustic or EM impedance and, therefore, to changes in lithology, porosity, interstitial fluid presence and thin layer identification (Chopra \& Marfurt, 2005). Instantaneous Phase allows tracking reflector continuity and, therefore, is useful for the detection of unconformities, faults and lateral changes in stratigraphy. Instantaneous Frequency and Bandwidth are employed in the identification of abnormal attenuations and very thin stratifications.

Figure 7 shows complex trace analysis applied to In-line 13 (Fig. 2). The four horizons traced in the radargrams separate five GPR sequences interpreted based on seismic stratigraphy concepts, like reflections terminations (onlaps, downlaps, etc.), and on their geophysical signatures for the various attributes. These sequences will be described later. In general, the Instantaneous Amplitude attribute has highs aligned near the upper limits of the
GPR sequences (Fig. 7C). The Instantaneous Phase attribute, on the other hand, emphasizes reflections continuities, highlighting their endings, like for example onlaps on Horizon H3 (Fig. 7D). The four horizons were traced on the radargram of this attribute. Finally, the responses of Instantaneous Frequency and Bandwidth attributes appear quite similar, with thin and elongated anomalies, whose concentration decreases with depth (Figs. 7E and 7F). Some of these anomalies are coincident with onlaps on horizons $\mathrm{H} 1$ and $\mathrm{H} 3$, facilitating their delimitation.

Another class of attributes is more directly related to the amplitude of reflections. The amplitude variations in GPR traces represent the classical basis of radargram interpretation (Forte et al., 2012). The amplitude interval has a more or less symmetrical oscillation around zero and depends on the medium impedance contrasts, depth of the reflectors, and distance between the transmitting and receiving antennas. Several attributes can be calculated from the amplitude values, such as Energy, Amplitude Variance, Hilbert Factor, among others. The Energy Attribute is defined as the measure of the reflectivity of the signal or the ratio of the squared sum of the amplitudes over the number of samples in a specific time window, with length close to the period of the signal's dominant frequency. This attribute is useful to highlight reflectors with low and/or irregular amplitudes, as well as to distinguish sequences with different impedance contrasts. In the study area, the $0.02 \mathrm{~m}$ interval was enough to cover the entire wavelength of individual reflections. High energy defines well the horizons $\mathrm{H} 2$ and $\mathrm{H} 3$ in the southern part of the GPR section, just like a zone of low energies allow delimiting Sequence 3 at its northern portion (Fig. 8G).

Amplitude Variance can be defined as the ratio of the reflection magnitude normalized by the average reflection magnitude. For a given time window, this attribute has a similar response to the Energy Attribute, being, however, less sensitive to lateral discontinuities such as fractures and faults (Barnes, 2007). This difference can be observed at the position close to $6.4 \mathrm{~m}$ and depths from 3.5 to $5.0 \mathrm{~m}$ (arrows in Fig. 8) where the Energy Attribute highlights a lateral subvertical discontinuity, barely visible in the Amplitude Variance Attribute (Figs. 8G and 8H, respectively). Some tilted reflectors in the northern portion of Sequence 5 are not well represented on the Amplitude Variance Attribute, denoting that this attribute is not the most suitable for the identification of inclined features in geological situations similar to those found in the study area.

The Hilbert transform serves not only as a starting point for the complex trace analysis, but also as seismic or GPR attribute (Chopra \& Marfurt, 2005). This attribute, known as the Hilbert 

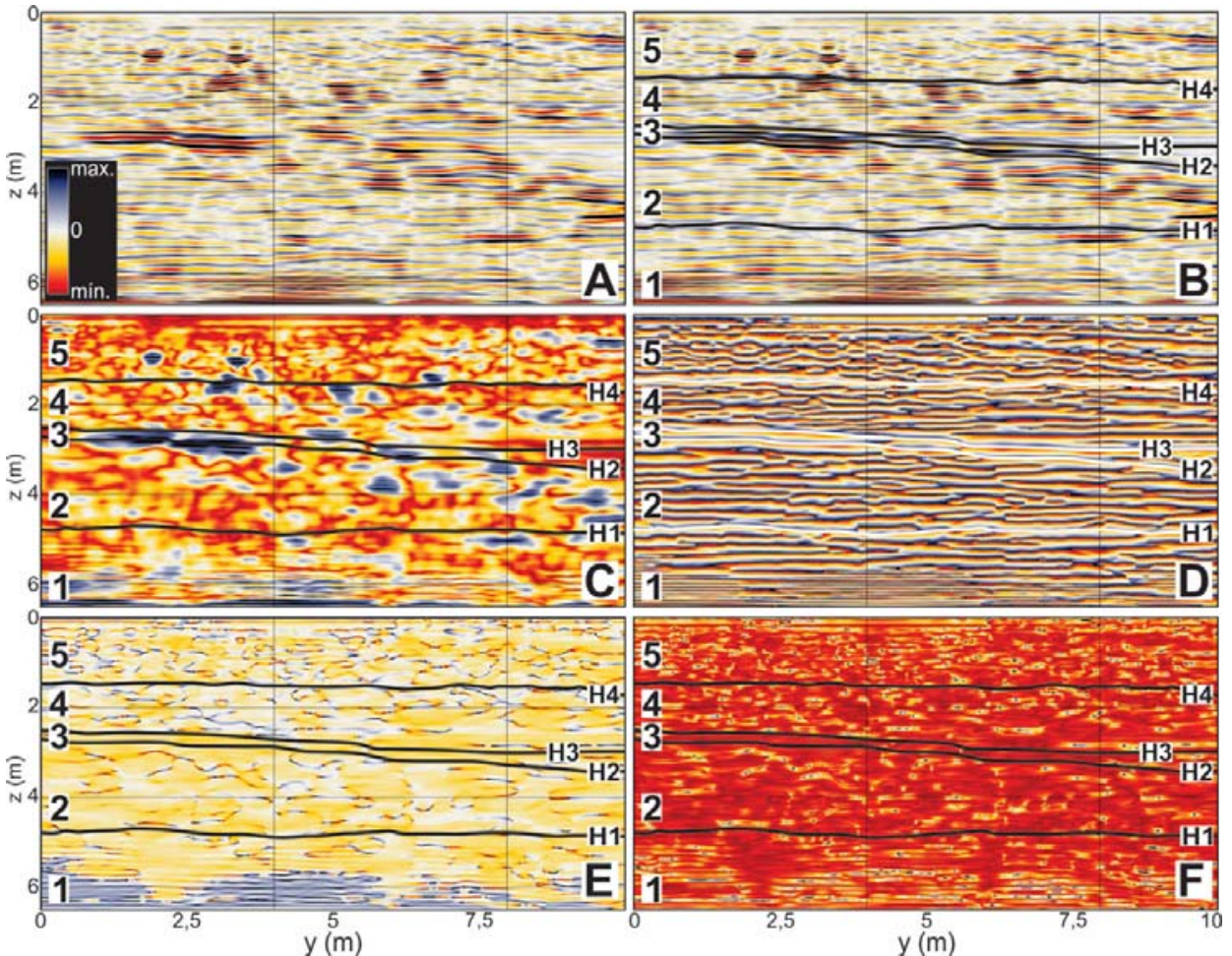

Figure 7 - Complex trace analysis of the processed (A) and interpreted (B) GPR section of In-line $13(\mathrm{~S} \rightarrow \mathrm{N})$. Instantaneous Attributes: $\mathrm{C}$-Amplitude; D - Phase; E - Frequency; $\mathrm{F}$ - Bandwidth. The table of colors in $(\mathrm{A})$ is valid for all radargrams.
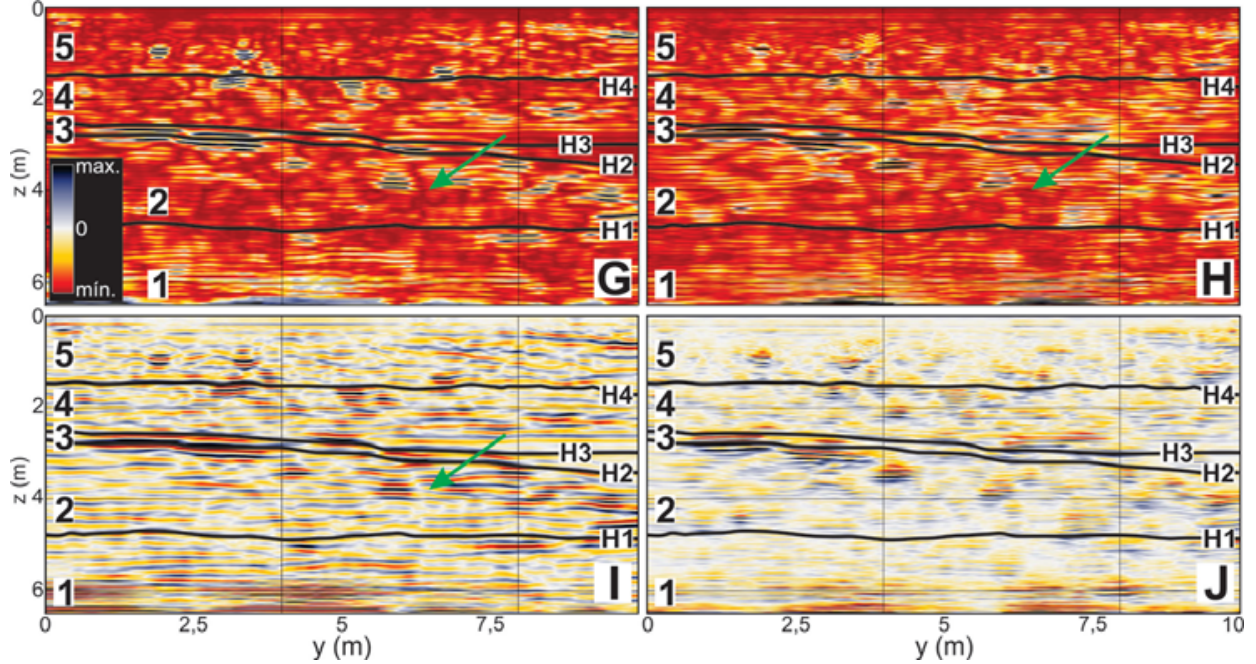

Figure 8 - Amplitude attributes of In-line $13(\mathrm{~S} \rightarrow \mathrm{N})$. G - Energy; $\mathrm{H}$ - Amplitude Variance; I - Hilbert Factor; J - Amplitude Variance of Hilbert Factor. The table of colors in $(G)$ is valid for all radargrams.

Factor, provides the magnitude of the geophysical signal from the detection of the reflections envelope. Its direct application in processed GPR data shows subtle differences (Figs. 7A and 8I). However, when applied on the Amplitude Variance Attribute it generates an aspect of self-relief in the radargram, enhancing re- flectors with high amplitudes like the horizons $\mathrm{H} 2$ and $\mathrm{H} 3$ in the southern portion of the GPR section (Fig. 8J).

The geometrical aspects of the reflections are highlighted by another attribute class. According to Taner (2001), the objective of geometric or directional attributes is to show the geometric 
characteristics of the seismic data, especially dips and undulations of beddings and stratigraphic and structural discontinuities. The main attributes of this category, discussed in this paper are Azimuth, Dip and Similarity. However, before applying these operators a steering cube is commonly generated, which calculates the local azimuth and dip values of the seismic or GPR reflectors for each trace sample (dGB Earth Sciences, 2011). By recognizing and following inclined reflectors, this cube produces results with better resolution for the application of structurally oriented filters (dip-steered median) and multi-trace attributes, obtaining input parameters optimized over the reflectors (dip-steered similarity), and calculating some compound attributes like Dip \& Azimuth, 3D curvature and Dip Variance.

The Azimuth and Dip attributes are, respectively, direction and magnitude parameters of the time gradient vector, starting from a reference point and calculated for each sample of an interpreted horizon (Dalley et al., 1989). The calculations are performed based on a reference plane which includes the GPR reflections from adjacent traces and focuses the calculated values in the reflection of the central trace. Similarity is a measure of distance that quantifies the similarity of two data vectors (de Rooij \& Tingdahl, 2002). It is a multi-trace attribute that returns the similarity properties trace by trace.

Figure 9 illustrates the directional volume and the results of directional attributes for the In-line 13. Although important lateral discontinuities or strongly tilted reflectors do not occur in the study area, it can be seen that some features are highlighted by these attributes. An increase in the anomalies frequency oc- curs from bottom to top, like in the Frequency and Bandwidth attributes (Figs. 7E and 7F). Between the horizons $\mathrm{H} 2$ and $\mathrm{H} 3$ and at the base of Sequence 4, these features are flatter and dip anomalies decrease. In this sequence, the GPR reflectors are subparallel and horizontal (Fig. 7). Inclined reflectors present in the northern portion of Sequence 5, can be recognized in directional attributes, even with their low expression radargram signatures (Fig. 9). Finally, the lateral subvertical discontinuity observed in the original radargram and Energy Attribute (Figs. 7 and 8), is subtly present in the Dip and Similarity Attributes (Figs. 9M and 9N), deemed unrepresentative in the local stratigraphy.

\section{D INTERPRETATION}

The four traced reflectors in each GPR section were interpolated to generate 3D horizons (Fig. 10), which mark aeolian dunes reactivation and correspond to third-order bounding surfaces, defined by Brookfield (1977). These boundaries are marked by sheets of heavy minerals. To correctly interpret the geologically significant reflectors in radargrams, recognizing the nature of aeolian strata, one needs to know the angle between the directions of GPR lines (NS and EW) and the dune field migration (NW-SE). Cuts perpendicular to the direction of transport generate more horizontal features (lower angle apparent dip), while cross sections show real dips.

$\mathrm{H} 1$ and $\mathrm{H} 2$ horizons define, respectively, the bottom and top of the lower stratum, characterized by a flat lower and an undulated upper surface. Horizon H1 (Fig. 10C) occurs between depths of 4.65 and $5.2 \mathrm{~m}$, uplifting in the east-central portion of the area.
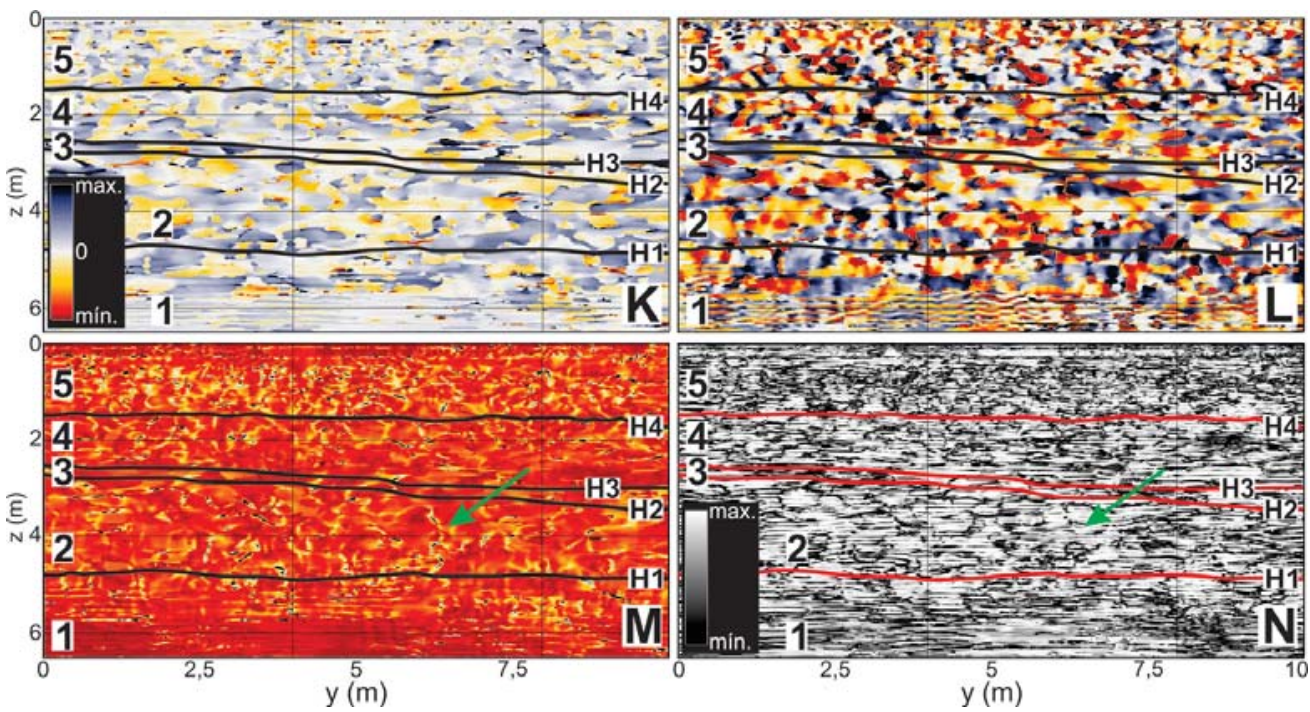

Figure 9 - Directional attributes of In-line $13(\mathrm{~S} \rightarrow \mathrm{N})$. K - Steering; L - Azimuth; $\mathrm{M}$ - Dip; $\mathrm{N}$ - Similarity. The table of colors in $(\mathrm{K})$ is valid for radargrams in $(\mathrm{L})$ and $(\mathrm{M})$. 

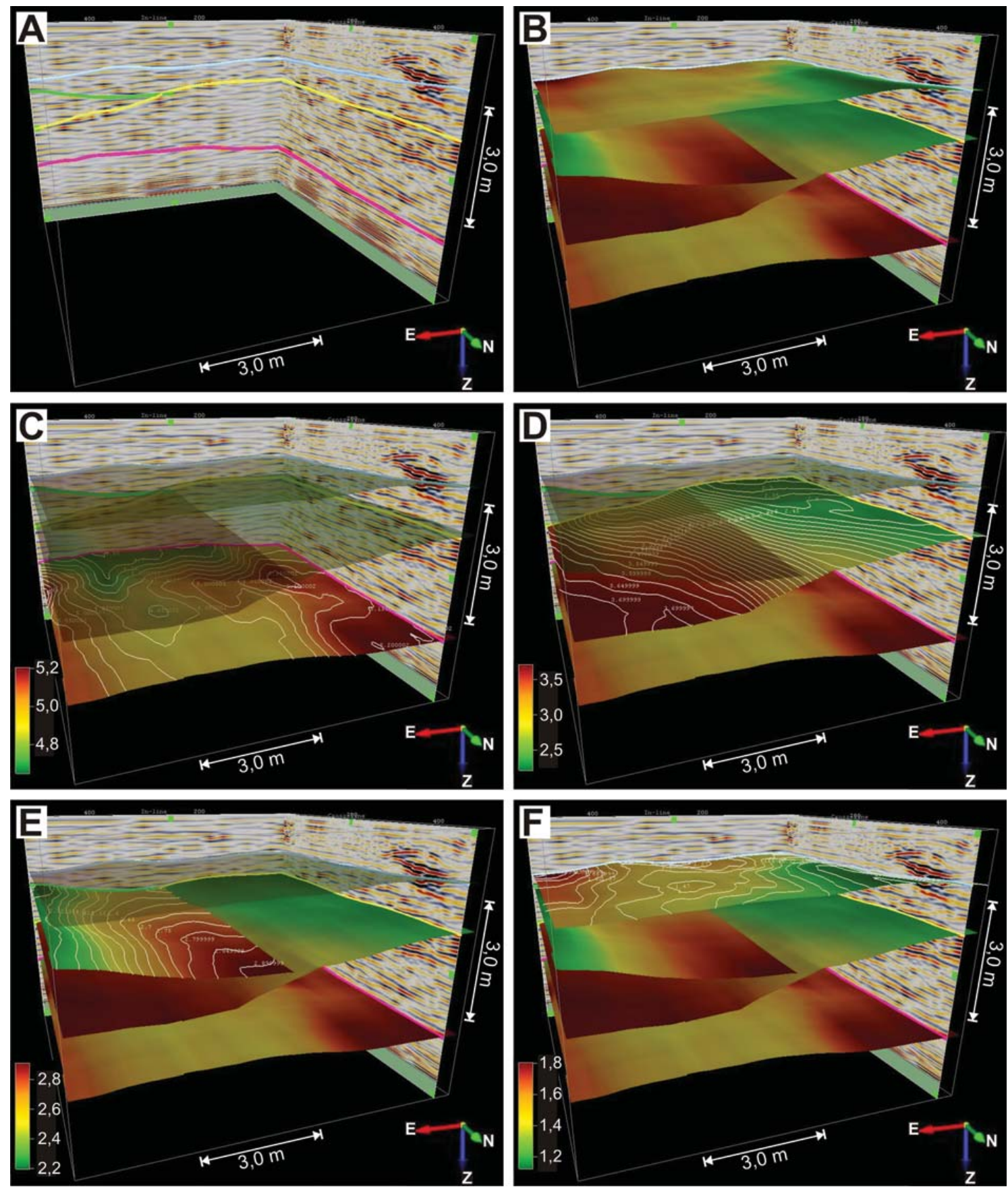

Figure 10 - Mapping of the main horizons traced on two perpendicular GPR sections (A) and interpolated for the entire study area (B). In the other 3D environments, each horizon is highlighted with depth isovalue lines ( $\mathrm{C}$ to $\mathrm{F}$ ).

In turn, the overlying Horizon H2 (Fig. 10D) marks the upper limit of this stratum whose thickness increases westward. Horizon H3 (Fig. 10E) filled the accommodation space provided by the top of Sequence 2 with the reflectors onlapping on the lower surface $\mathrm{H} 2$. To the west it is bounded by the underlying horizon, with depths ranging between 2.1 and $2.9 \mathrm{~m}$. Finally, the boundary surface which marks horizon $\mathrm{H} 4$ (Fig. 10F) in the uppermost portion is essentially flat with few undulations and a gentle slope towards SE, showing a variation in depths not exceeding $0.7 \mathrm{~m}$.

Such horizons separate five strata, identified by reflections terminations patterns, reflectors behavior and their GPR signatures for the calculated attributes. From base to top, Sequence 1 


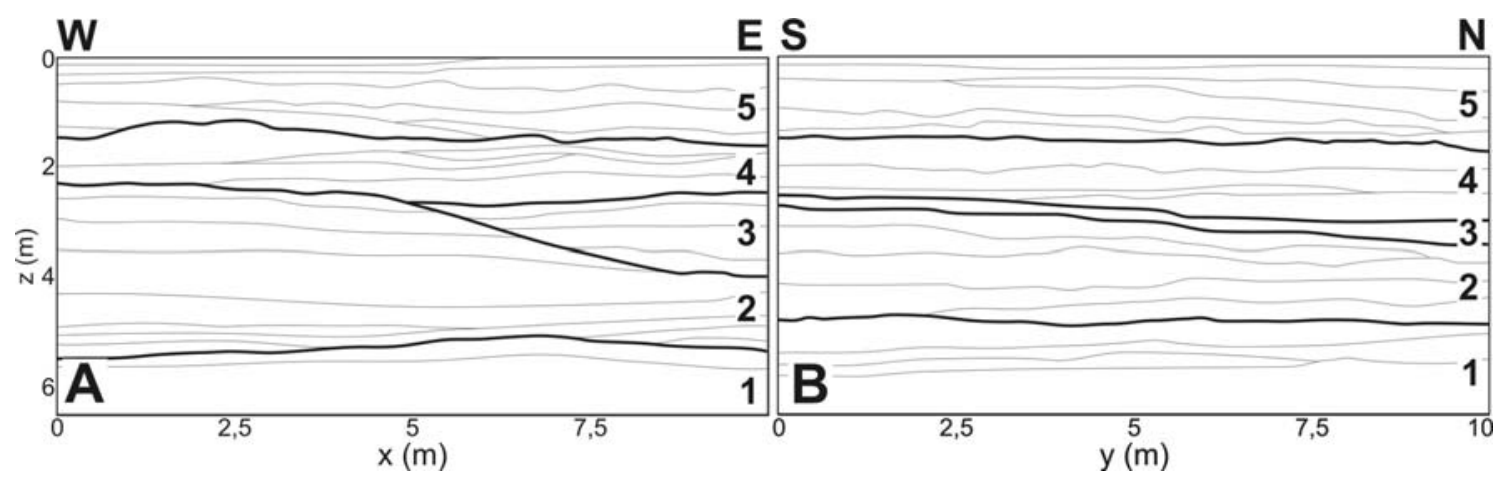

Figure 11 - Seismic-stratigraphic sections of the study area along the longitudinal (A) and transverse (B) directions.

shows continuous and sub-horizontal reflectors, with gentle SW dip and rare northward onlaps (Fig. 11). Sequence 2 also consists of plane-parallel sub-horizontal reflectors, with onlaps and downlaps over local elevations of the basal horizon and apparent truncations at the top. This sequence presents wedge geometry (Fig. 10). Sequence 3 is marked by horizontal reflectors with westward onlap (Fig. 11). This stratigraphic unit occurs only in the eastern part of the study area. Sequence 4 consists of subparallel wedge or lenticular reflectors, with SW onlaps. In the upper portion, Sequence 5 shows sloping, wedge and horizontal reflectors, dipping at low angle to NE, with NW onlaps and NE downlaps (Fig. 11).

Despite the small size of the surveyed area, some considerations on the nature and the geometry of the deposits, the hierarchy of bounding surfaces, and the sedimentary structures can be made. This is a deposit of inactive aeolian dunes where 05 strata are present. The depositional surfaces imaged in this survey result from reactivation of aeolian dunes, responding to variations in wind velocity, which can be classified as third order bounding surfaces, according to the classification of Brookfields (1977). Because it is an oblique cut to the main direction of the aeolian transport, the sedimentary structures appear essentially sub-horizontal or with small dip; their geometry slightly tabular, sometimes lenticular or wedge, shows the expression of the dunes in this direction (almost frontal).

Moura et al. (2006) describe radar facies of a coastal aeolian dunes field near Natal, whose EM response is quite similar to the GPR of the study area. Making a direct analogy with the more superficial radar facies performed by these authors, GPR sequences of this survey may be considered as deriving from processes of migration of sand bodies of long wavelength, which happen in the upper portion of the back of the dunes (windward). Such features reach up to tens of meters, as with the dunes in the above two cases.

\section{CONCLUSIONS}

The application of techniques for acquisition, processing and interpretation of GPR data acquired in two orthogonal directions, illustrates the advantages of $3 \mathrm{D}$ surveys in the detection and imaging of buried targets and depositional features. The 42 inand cross-lines allowed to generate a much more realistic GPR volume of three-dimensional behavior of the investigated substrate. Regarding geophysical data processing, a filtering routine was formed based on temporal and spectral analysis of GPR traces after each application of the computational procedure. The seven processing stages improved substantially the radargrams by deleting the signal content from EM induction between antennas and addressing the signal attenuation with depth. A model of EM waves propagation velocity was obtained from the velocity analysis in hyperbolas and two CMP data. Based on this model, the migration of the reflectors and the GPR sections time/depth conversion were performed.

A series of instantaneous amplitude and geometry attributes was used to aid in the seismic-stratigraphy interpretation of the GPR sections. Instantaneous Amplitude, Energy, Amplitude Variance, and Hilbert Factor Amplitude Variance attributes contributed to distinguish five GPR sequences according to their distinct signatures. While the horizons that separate such sequences could be more easily traced with the Instantaneous Phase attribute. Terminations of reflections (onlaps, downlaps, etc.) over such horizons were well highlighted by Instantaneous Frequency and Instantaneous Bandwidth attributes. Finally, geometric and Energy attributes highlighted the tilted reflectors and the few discontinuities present in the surveyed area.

The internal geometry of sedimentary strata, obtained in the GPR volume, can be reconstructed in three-dimensional environment. This spatial information enables understanding the nature of the imaged deposits, considered here as aeolian dunes, like: a) the hierarchy of reflectors, interpreted as corresponding to 3rd 
order bounding surfaces; b) sedimentary structures, which in an oblique cut of the main transport direction appear as low-angle or horizontal cross-stratification; and c) the geometry of the deposits, where tabular wedge or lens shaped bodies predominate. These characteristics are typical of aeolian dunes deposits, resulting from sandy bodies' migration in coastal regions.

\section{ACKNOWLEDGMENTS}

The authors thank dGB Earth Sciences company for granting an educational license of Opendtect v 4.2 software. DLC thanks his $\mathrm{PQ/CNPq}$ grants and JARJ, WLET and VAS thanks their CNPq and CAPES scholarships.

\section{REFERENCES}

ANGELIM LAA. 2006. Geologia e recursos minerais do Estado do Rio Grande do Norte. CPRM - Serviço Geológico do Brasil, Recife, 119 pp.

ANNAN AP. 1996. Transmission dispersion and GPR. Journal of Environmental and Engineering Geophysics, 2(2): 125-136.

ANNAN AP. 1999. Practical processing of GPR data. Sensors and Software Inc., Mississauga, ON, Canada, 249 pp.

ANNAN AP, WALLER WM, STRANGWAY DW, ROSSITER JR, REDMAN JD \& WATTS RD. 1975. The electromagnetic response of a low-loss, 2-layer, dielectric earth for horizontal electric dipole excitation. Geophysics, 40(2): 285-298.

BANO M. 1996. Constant dielectric losses of ground-penetrating radar waves. Geophysical Journal International, 124: 279-288.

BARNES AE. 2007. Redundant and useless seismic attributes. Geophysics, 72(3): P33-P38.

BARRETO AMF, SUGUIO K, BEZERRA FHR, TATUMI SH, YEE M \& GIANNINI PCF. 2004. Geologia e geomorfologia do quaternário costeiro do Estado do Rio Grande do Norte. Boletim IG - USP: Série Científica, 4(2): 1-12.

BÖNIGER U \& TRONICKE J. 2010. Improving the interpretability of 3D GPR data using target-specific attributes: application to tomb detection. Journal of Archaeological Science, 37: 360-367.

BROOKFIELD ME. 1977. The origin of bounding surface in ancient aeolian sandstones. Sedimentology, 24: 303-332.

CARCIONE JM, MARCAK H, SERIANI G \& PADOAN G. 2000. GPR modeling study in a contaminated area of Krzywa air base (Poland). Geophysics, $65(2)$ : 521-525.

CASSIDY NJ. 2007. A review of practical numerical modelling methods for the advanced interpretation of ground-penetrating radar in nearsurface environments. Near Surface Geophysics, 5(1): 5-21.
CASSIDY NJ. 2009. Ground Penetrating Radar data processing, modelling and analysis. In: JOL HM (Ed.). Ground Penetrating Radar Theory and Applications. Elsevier, New York, p. 141-176.

CHOPRA S \& MARFURT KJ. 2005. Seismic attributes - A historical perspective. Geophysics, 70(5): 3S0-28S0.

CORBEANU RM, McMECHAN GA, SZERBIAK RB \& SOEGAARD $K$. 2002. Prediction of 3-D fluid permeability and mudstone distributions from ground-penetrating radar (GPR) attributes: Example from the Cretaceous Ferron Sandstone member, east-central Utah. Geophysics, 67: 1495-1504.

DALLEY RM, GEVERS EEA, STAMPLI GM, DAVIES DJ, GASTALDI CN, RUIJETNBERG PR \& VERMEER GJD. 1989. Dip and azimuth displays for 3-D seismic interpretation. First Break, 7(1): 86-95.

DANIELS DJ. 2007. Ground Penetrating Radar. IEE Radar, Sonar, Navigation and Avionics Series 15. 2nd ed., The Institution of Electrical Engineers, London, UK, $726 \mathrm{pp}$.

DANIELS DJ. 2008. Ground Penetrating Radar. In: SKOLNIK MI (Ed.). Radar Handbook. McGraw Hill, New York, p. 21.1-21.41.

DANIELS JJ, GRUMMAN D \& VENDL M. 1997. Coincident antenna Three-Dimensional GPR. Journal of Environmental \& Engineering Geophysics, 2(1): 1-9.

DAVIS JL \& ANNAN AP. 1989. Ground penetrating radar for highresolution mapping of soil and rock stratigraphy. Geophysical Prospecting, 37: 531-551.

DE CASTRO DL \& CASTELO BRANCO RMG. 2003. 4-D Ground Penetrating Radar monitoring of a hydrocarbon leakage site in Fortaleza (Brazil) during its remediation process: a case history. Journal of Applied Geophysics, 54(1-2): 127-144.

DE ROOIJ M \& TINGDAHL K. 2002. Meta-attributes - the key to multivolume, multiattribute interpretation. The Leading Edge, 21(10): 10501053.

DEEDS J \& BRADFORD J. 2002. Characterization of an aquitard and direct detection of LNAPL at Hill Air Force Base using GPR AVO and migration velocity analyses. Proceedings of SPIE - The International Society for Optical Engineering, 4758: 323-329.

DGB EARTH SCIENCES. 2011. Introduction to OpendTect: Training manual. dGB Earth Sciences B.V., Enschede, Netherlands, 129 pp.

FORTE E, PIPAN M, CASABIANCA D, DI CUIA R \& RIVA A. 2012. Imaging and characterization of a carbonate hydrocarbon reservoir analogue using GPR attributes. Journal of Applied Geophysics, 81: 76-87.

GRASMUECK M, WEGER R \& HORSTMEYER H. 2005. Full-resolution 3-D GPR imaging. Geophysics, 70(1): K12-K19.

HERMOZILHA H, GRANGEIA C \& SENOS MATIAS M. 2010. An integrated 3D constant offset GPR and resistivity survey on a sealed landfill - Ilhavo, NW Portugal. Journal of Applied Geophysics, 70: 58-71. 
HOLLENDER F \& TILLARD S. 1998. Modeling ground-penetrating radar wave propagation and reflection with the Jonscher parameterization. Geophysics, 63: 1933-1942.

JOL HM. 2009. Ground Penetrating Radar Theory and Applications. Elsevier, New York, 524 pp.

KADIOGLU S. 2008. Photographing layer thicknesses and discontinuities in a marble quarry with 3D GPR visualization. Journal of Applied Geophysics, 64: 109-114.

KEARY P, BROOKS M \& HILL I. 2009. Geofísica de Exploração. Oficina de Textos, São Paulo, 438.

LAI WL, TSANG WF, FANG H \& XIAO D. 2006. Experimental determination of bulk dielectric properties and porosity of porous asphalt and soils using GPR and a cyclic moisture variation technique. Geophysics, 71(4): K93-K102.

LAHOUAR S \& AL-QADI IL. 2008. Automatic detection of multiple pavement layers from GPR data. NDT\&E International, 41(1): 69-81.

MOURA MVM, REYES-PÉREZ YA, GAUW DS, SILVA DAS, SOUZA AM, PELOSI APMR \& LIMA-FILHO FP. 2006. Levantamento geofísico com GPR em um campo de dunas eólicas em Tibau do Sul/RN. Revista de Geologia, 19(1): 99-108.

NEGRI S, LEUCCI G \& MAZZONE F. 2008. High resolution 3D ERT to help GPR data interpretation for researching archaeological items in a geologically complex subsurface. Journal of Applied Geophysics, 65: 111-120.

NOVO A, GRASMUECKM, VIGGIANO DA \& LORENZO H. 2008. 3D GPR in Archeology: What can be gained from dense Data Acquisition and Processing? In: 12th International Conference on Ground Penetrating Radar, Extended Abstract, Birmingham, UK, 5 pp.

NYQUIST H. 1928. Certain topics in telegraph transmission theory. Transactions of the American Institute of Electrical Engineers, 47: 617644.

PEREIRA AJ, GAMBÔA LAP, SILVA MAM, RODRIGUES AR \& COSTA A. 2003. A utilização do Ground Penetrating Radar (GPR) em estudos de estratigrafia na praia de Itaipuaçú - Maricá (RJ). Brazilian Journal of Geophysics, 21(2): 163-172.

REDMAN JD, DERYCK SM \& ANNAN AP. 1994. Detection of LNAPL pools with GPR: theoretical modeling and surveys of a controlled spill.
In: Fifth International Conference on Ground Penetrating Radar (GPR'94), Proceedings... Kitchener, Ontario, Canada, Expanded Abstract, 12831294.

ROBERTS RL \& DANIELS JJ. 1996. Analysis of GPR polarization phenomena. JEEG, 1(2): 139-157.

ROSSETTIDF, GÓES AM \& SOUZA LSB. 2001. Estratigrafia da sucessão sedimentar Pós-Barreiras (Zona Bragantina, Pará) com base em Radar de Penetração no Solo. Brazilian Journal of Geophysics, 19(2): 113-130.

SENECHAL P, PERROUD H \& SENECHAL G. 2000. Interpretation of reflection attributes in a 3-D GPR survey at Vallée d'Ossau, western Pyrenees, France. Geophysics, 65(5): 1435-1445.

SOUZA LAP, PORSANI JL, SOUZA OC \& MOUTINHO L. 2002. Levantamento Experimental GPR no Rio Taquari, Bacia do Pantanal Matogrossense. Brazilian Journal of Geophysics, 20(1): 67-72.

TANER MT. 2001. Seismic Attributes. Canadian Society of Exploration Geophysicists Recorder, 26(7): 48-56.

TANER MT, KOEHLER F \& SHERIFF RE. 1979. Complex trace analysis. Geophysics, 44: 1041-1063.

VERSTEEGR. 1996. Optimization of GPR Acquisition and Noise Elimination Parameters. In: 6th International Conference on Ground Penetrating Radar (GPR'96), Sendai, Japan, p. 289-292.

XAVIER NETO P. 2006. Processamento e interpretação de dados 2D e 3D de GPR: aplicações no imageamento de feições kársticas e estruturas de dissolução no campo de petróleo de Fazenda Belém - CE. Doctorate thesis, UFRN, Natal, $177 \mathrm{pp}$.

XAVIER NETO P \& MEDEIROS WE. 2006. A practical approach to correct attenuation effects in GPR data. Journal of Applied Geophysics, 59: 140-151.

YILMAZ 0. 2008. Seismic Data Analysis: Processing, Inversion, and Interpretation of Seismic Data. Investigations in Geophysics No. 10 (v. 1\&2). Society of Exploration Geophysicists, Tulsa, USA, Electronic Edition, $2027 \mathrm{pp}$.

YOUNG RA \& SUN J. 1999. Revealing stratigraphy in ground penetrating radar data using domain filtering. Geophysics, 64: 435-442. 


\section{NOTES ABOUT THE AUTHORS}

David Lopes de Castro is a geologist from UFRN, Master in Geophysics from UFPA and Ph.D. in Geophysics from the Christian-Albrechts Universität (Kiel - Germany). Currently, is an Associate Professor at the Universidade Federal do Rio Grande do Norte. Operates in Geosciences with emphasis in Applied Geophysics in the study of sedimentary basins, regional geophysical mapping, hydrogeology and environment. Member of the Brazilian Geophysical Society, the Brazilian Geological Society and Society of Exploration Geophysicists.

João Andrade dos Reis Júnior has a Physics degree from Universidade Federal do Pará (2007), MSc. and Ph.D. in Geophysics from the Universidade Federal do Pará (2009) and Universidade Federal do Rio Grande do Norte (2014), respectively. Currently, is Professor at the Universidade Federal Rural da Amazônia - Campus de Parauapebas. Has experience in the area of Applied Geophysics with emphasis on collection, processing and analysis of GPR data.

Washington Luiz Evangelista Teixeira graduated in Engineering and Computing from UFC, has a MSc. in Petroleum Engineering and is Ph.D. in Geophysics and Geodynamics at the UFRN (2013). Currently, works at DNOCS as engineer and researcher using shallow geophysics in the areas of hydrology, environment, and engineering, with emphasis on earth dams.

Victor de Albuquerque Silva is a geologist from UFRN (2011), and MSc. in Geophysics at the UFRN (2013). Currently, works in Petrobras (Natal, Rio Grande do Norte State).

Francisco Pinheiro Lima Filho is a geologist from UFC, MSc. and Ph.D. in Sedimentary Geology from the USP (São Paulo). Currently, works as Associate Professor and Coordinator of the Stratigraphic Analysis Laboratory, in the Departamento de Geologia da Universidade Federal do Rio Grande do Norte. Operates in Geosciences with emphasis in Petroleum Geology, Sedimentary Geology and Applied Geophysics. Member of the Brazilian Geological Society. 